\title{
a-Tocopherol modifies the expression of genes related to oxidative stress and apoptosis during in vitro maturation and enhances the developmental competence of rabbit oocytes
}

\author{
M. Arias-Álvarez, R. M. García-García, J. López-Tello, P. G. Rebollar,
} A. Gutiérrez-Adán and P. L. Lorenzo

\begin{abstract}
The developmental competence of in vitro maturation (IVM) oocytes can be enhanced by antioxidant agents. The present study investigated, for the first time in the rabbit model, the effect of adding $\alpha$-tocopherol $(0,100,200$ and $400 \mu \mathrm{M}$ ) during IVM on putative transcripts involved in antioxidant defence (superoxide dismutase 2, mitochondrial (SOD2), glutathione peroxidase 1 (GPX1), catalase (CAT)), cell cycle regulation and apoptosis cascade (apoptosis tumour protein 53 (TP53), caspase 3, apoptosis-related cysteine protease (CASP3)), cell cycle progression (cellular cycle V-Akt murine thymoma viral oncogene homologue $1(A K T I)$ ), cumulus expansion (gap junction protein, alpha 1, $43 \mathrm{kDa}(G J A I)$ and prostaglandin-endoperoxide synthase 2 (prostaglandin $\mathrm{G} / \mathrm{H}$ synthase and cyclo-oxygenase) (PTGS2)) and metabolism (glucose-6-phosphate dehydrogenase $(G 6 P D)$ ). Meiotic progression, mitochondrial reallocation, cumulus cell apoptosis and the developmental competence of oocytes after IVF were also assessed. Expression of SOD2, CAT, TP53, CASP3 and $G J A 1$ was downregulated in cumulus-oocyte complexes (COCs) after IVM with $100 \mu \mathrm{M} \alpha$-tocopherol compared with the group without the antioxidant. The apoptotic rate and the percentage of a non-migrated mitochondrial pattern were lower in COCs cultured with $100 \mu \mathrm{M} \alpha$-tocopherol, consistent with better-quality oocytes. In fact, early embryo development was improved when $100 \mu \mathrm{M} \alpha$-tocopherol was included in the IVM medium, but remained low compared with in vivomatured oocytes. In conclusion, the addition of $100 \mu \mathrm{M} \alpha$-tocopherol to the maturation medium is a suitable approach to manage oxidative stress and apoptosis, as well as for increasing the in vitro developmental competence of rabbit oocytes.
\end{abstract}

\section{Introduction}

In vitro maturation (IVM) has become an effective method to produce competent oocytes for a wide range of applications in assisted reproductive technologies (ARTs), such as human ARTs, animal cloning, genetic resources and fertility preservation, as well as for basic research. However, the current potential of IVM oocytes remains lower than for in vivo-matured oocytes (Rizos et al. 2002; Arias-Álvarez et al. 2017). Oxidative stress has recently appeared as one of the most important factors contributing to low oocyte quality in vitro. Standard culture conditions induce oxidative stress in the cell due to an imbalance between oxidants and antioxidant defence mechanisms, subsequently increasing concentrations of reactive oxygen species (ROS). ROS production is a normal internal process of cells, 
including in oocytes and embryos. However, excessive ROS concentrations induce a cascade of chain reactions that can ultimately lead to lipid peroxidation in membrane phospholipids, affecting the function and permeability of cell membranes, and generating DNA damage, meiotic arrest and mitochondrial dysfunction, which, in turn, activate caspase cascades and culminate in irreversible cell death (Combelles et al. 2009; Tripathi et al. 2009). Oxidative oocyte injury is detrimental to fertility potential (Guérin et al. 2001) and early embryo development (Kitagawa et al. 2004), and may increase the risk of miscarriage (for a review, see Agarwal et al. 2012). Therefore, the presence of antioxidant substances in the oocyte microenvironment would effectively minimise oxidative stress and benefit in vitro oocyte maturation processes.

Vitamin $\mathrm{E}$ is one of the most widely studied non-enzymatic antioxidant agents because it is the primary free radical scavenger in the mammalian cell membrane (Chow 1991). $\alpha$-Tocopherol is the most active form of vitamin $\mathrm{E}$ and a natural antioxidant. It is a lipid-soluble vitamin that protects polyunsaturated fatty acids in membranes and inhibits lipid peroxidation, maintaining cell membrane function. Thus, $\alpha$-tocopherol protects against cell damage induced by oxidative stress (Tao et al. 2010 ), and acts as a modulator of many intracellular or extracellular biochemical processes (Azzi and Stocker 2000). In the mammalian ovary, $\alpha$-tocopherol is the most important antioxidant that provides cell defence against ROS. It is present in follicular fluid in both animals and humans (Cassano et al. 1999; Palini et al. 2014), and it plays an important role as a local precursor of retinoids, which may be relevant for follicular development and oocyte maturation (Schweigert et al. 2003). These findings make $\alpha$-tocopherol a candidate non-invasive agent for improving IVM efficiency. During IVM, $\alpha$-tocopherol content in the membranes of cumulus-oocyte complexes (COCs) diminishes by $50 \%$, suggesting a partial loss of its antioxidant activity (Dalvit et al. 2005). Supplementation of culture media with $\alpha$-tocopherol improved granulosa cell viability (McCluskey et al. 1999), folliculogenesis, oocyte quality, fertilisation rates and in vitro early embryo development in cattle (Olson and Seidel 2000), gilts (Kitagawa et al. 2004; Tao et al. 2010; Tareq et al. 2012) and sheep (Natarajan et al. 2010). $\alpha$-Tocopherol also protects oocytes during IVM against the deleterious effects of cryoprotectants in vitrified ovaries (Farzollahi et al. 2016; Yashiro et al. 2015), and increases the blastocyst rate of somatic cell nuclear transfer (SCNT) embryos (Jeong et al. 2006; Wongsrikeao et al. 2007). Therefore, although the relationship between $\alpha$-tocopherol and oocyte maturation and embryo development is well established in different species, no studies to date have been performed in the rabbit.

Rabbits are used as livestock and as a model for basic reproduction research (Fischer et al. 2012; López-Tello et al. 2017 ) because they share many biochemical and physiological features with humans (Fan and Watanabe 2003; Ogonuki et al. 2005). The development of suitable IVM, IVF and in vitro culture (IVC) techniques in this species is crucial because these techniques are useful in biotechnology to produce SCNT embryos for animal breeding, the preservation of genetic resources, developmental biology studies and as model system for human reproduction. However, the IVM method in rabbits is poorly developed compared with other species due to the difficulty of achieving optimal rates of in vitro oocyte maturation, and currently there is limited information about the cellular and molecular mechanisms controlling oocyte maturation. Oxidative stress could be a key factor determining the low developmental competence in this species. Therefore, understanding cellular and molecular mechanisms during rabbit maturation in response to antioxidants could provide important information in order to find optimal media for use in animal and human ARTs.

In the present study, a dose-response experiment was performed to determine whether $\alpha$-tocopherol has a direct effect on meiotic and cytoplasmic in vitro oocyte maturation events. Furthermore, the effects of $\alpha$-tocopherol on the apoptotic index in cumulus cells, the mRNA expression patterns of some important genes related to crucial mechanisms in oocytes and cumulus cells (CCs) and early embryo development after IVF were examined in the rabbit model.

\section{Materials and methods}

Unless stated otherwise, all chemicals were purchased from Sigma Chemicals.

\section{Experimental design}

\section{Experiment 1: effects of $\alpha$-tocopherol on markers of} nuclear and cytoplasmic oocyte maturation

A dose-response experiment was performed to assess the direct effect of $\alpha$-tocopherol on markers of nuclear and cytoplasmic oocyte maturation. Serum-free maturation medium was supplemented with or without $\alpha$-tocopherol $(0,100,200$ or $400 \mu \mathrm{M}$ ). Experiment 1a assessed: (1) oocyte meiotic progression by investigating the MII rate and phosphorylation of extracellular signal-regulated kinase (ERK) $1 / 2$; and (2) cytoplasmic maturation, based on determination of mitochondrial distribution patterns. Experiment $1 \mathrm{~b}$ analysed apoptosis in CCs and the expression of putative transcripts involved in essential events for oocyte maturation, namely cumulus expansion (gap junction protein, alpha 1, $43 \mathrm{kDa}(G J A 1)$, prostaglandin-endoperoxide synthase 2 (prostaglandin $\mathrm{G} / \mathrm{H}$ synthase and cyclo-oxygenase) (PTGS2)), antioxidant defence (superoxide dismutase 2, mitochondrial (SOD2), glutathione peroxidase 1 ( $G P X 1)$, catalase $(C A T)$ ), cell cycle regulation and the apoptosis cascade (apoptosis tumour protein 53 (TP53); caspase 3, apoptosis-related cysteine protease (CASP3)), cell cycle progression and viability (cellular cycle $\mathrm{V}$-Akt murine thymoma viral oncogene homologue 1 $(A K T 1)$ ) and metabolism (glucose-6-phosphate dehydrogenase $(G 6 P D))$ in rabbit oocytes and their CCs.

\section{Experiment 2: effects of $\alpha$-tocopherol on the developmental competence of oocytes}

IVM oocytes that had been cultured with $100 \mu \mathrm{M}$ $\alpha$-tocopherol (which showed the best results in Experiments $1 \mathrm{a}$ and $1 \mathrm{~b}$ ) or without $\alpha$-tocopherol (control) were used for IVF and IVC. In addition, in vivo-matured oocytes were used for IVF and IVC. Early embryo development was evaluated until the blastocyst stage. 


\section{Oocyte collection and IVM}

Oocytes for IVM were recovered from adult New Zealand $x$ California white rabbit dams (Oryctolagus cuniculus) located in the facilities of the Polytechnic University of Madrid.

Ovaries were obtained by mid-ventral laparotomy of dams after they had been sedated with $35 \mathrm{mg} \mathrm{kg}^{-1}$ ketamine (Imalgene 1000; Merial); dams were killed with an intravenous bolus of barbiturate ( $30 \mathrm{mg} \mathrm{kg}{ }^{-1}$; Dolethal; Vetoquinol). All procedures were performed in accordance with the policies of the University Scientific Ethics Committee and the Spanish Policy for Animal Protection (Royal Decree 53/2013), and approved by the Animal Ethics Committee of the Community of Madrid (Ref. PROEX 302/15) and met the European Union directive about the protection of animals used in experiments.

Ovarian follicles $\geq 1 \mathrm{~mm}$ in diameter were aspirated under a stereoscopic microscope (Nikon), and COCs were selected based on their morphological appearance, as described previously (Arias-Álvarez et al. 2010). COCs were cultured in fourwell dishes in groups of $30-40 \mathrm{COCs}$ per well for $16 \mathrm{~h}$ at $38^{\circ} \mathrm{C}$ under an atmosphere of $5 \% \mathrm{CO}_{2}$ in air with maximum humidity.

The maturation medium consisted of tissue culture media (TCM)-199 with $2 \mathrm{mM}$ L-glutamine, $0.1 \mathrm{mg} \mathrm{mL}^{-1}$ sodium pyruvate and $0.3 \% \mathrm{w} / \mathrm{v}$ bovine serum albumin (BSA). For Experiments $1 \mathrm{a}$ and $1 \mathrm{~b}$, a serum-free medium was used, as previously reported (Arias-Alvarez et al. 2017). The IVM medium included $10 \mathrm{ng} \mathrm{mL}^{-1}$ epidermal growth factor (EGF) and $0,100,200$ or $400 \mu \mathrm{M} \alpha$-tocopherol (T3251; Groups $0 \mathrm{E}$, $100 \mathrm{E}, 200 \mathrm{E}$ and $400 \mathrm{E}$ respectively). $\alpha$-Tocopherol was dissolved in ethanol and stored at $4^{\circ} \mathrm{C}$ in the dark. Prior to culture, appropriate dilutions of this stock solution were made in maturation medium by vortexing for $2 \mathrm{~h}$. The final ethanol concentration was $<0.05 \%$ in all experimental groups. Final concentrations of $\alpha$-tocopherol in the maturation medium were checked by HPLC.

To assess the beneficial effect of $\alpha$-tocopherol on blastocyst yield (Experiment 2), oocytes were matured in vitro with or without $100 \mu \mathrm{M} \alpha$-tocopherol in a serum-free medium (Groups $100 \mathrm{E}$ and $0 \mathrm{E}$ (control) respectively). In order to improve the rate of in vitro embryo development, a suitable IVM medium used previously in rabbit species because of its results (Lorenzo et al. 1996; Arias-Álvarez et al. 2010) was used in the present study. This medium contained $10 \mathrm{ng} \mathrm{mL}^{-1} \mathrm{EGF}, 100 \mathrm{ng} \mathrm{mL}^{-1}$ insulin growth factor 1 (IGF1) and $10 \% \mathrm{v} / \mathrm{v}$ fetal calf serum (FCS). The IVM oocytes cultured in this medium with or without $100 \mu \mathrm{M}$ $\alpha$-tocopherol are referred to Groups 100E-FCS and 0E-FCS (control) respectively.

To obtain in vivo-matured COCs, 12 dams were killed $15 \mathrm{~h}$ after the induction of ovulation by intramuscular injection of gonadorelin ( $20 \mathrm{mg}$; Inducel-GnRH; Ovejero), a synthetic analogue of gonadotrophin-releasing hormone that stimulates the synthesis and release of endogenous LH from the anterior pituitary gland. Ovulated oocytes were recovered by flushing the reproductive tract with phosphate-buffered saline (PBS) supplemented with $1 \mathrm{mg} \mathrm{mL}^{-1}$ polyvinylpolypyrrolidone (PVP).

Oocyte quality markers during oocyte maturation in Experiments $1 \mathrm{a}$ and $1 \mathrm{~b}$ were analysed in five replicates $(n=731$ COCs). Oocyte developmental competence following IVM,
IVF and IVC in Experiment 2 was assessed in three replicates $(n=618 \mathrm{COCs})$.

\section{Nuclear maturation and mitochondrial distribution in oocytes}

Nuclear maturation, measured as the MII rate, and cytoplasmic maturation (assessed on the basis of mitochondrial patterns) were evaluated in 100 oocytes after IVM $(n=46,16,20$ and 18 in Groups 0E, 100E, 200E and 400E respectively) by confocal scanning microscopy. Briefly, CCs were mechanically removed, and denuded oocytes were incubated with $200 \mu \mathrm{M}$ MitoTracker Orange probe (Invitrogen) at $38^{\circ} \mathrm{C}$ for $30 \mathrm{~min}$ for mitochondrial staining, followed by $1 \mu \mathrm{g} \mathrm{mL}^{-1}$ Hoechst 33342 dye for 30 at room temperature for nuclear staining. Samples were observed under a laser scanning confocal microscope (TCS SP2; Leica) using $546 \mathrm{~nm}$ and $351 / 364 \mathrm{~nm}$ excitation lasers to visualise mitochondria and chromosomes respectively. Five sections taken every $5 \mu \mathrm{m}$ were made for each oocyte and a maximum projection was made for each one. The mitochondrial migration pattern was observed at a magnification of $\times 40$ and classified according to Arias-Álvarez et al. (2017) as follows: migrated homogeneous ( $\mathrm{MH})$, in which there is high fluorescence in the cortical area and moderate fluorescence throughout the cytoplasm; migrated clustered (MC), in which there is fluorescence in the cortical area with aggregates; diffused homogeneous (DH), in which the fluorescence is dispersed throughout the cytoplasm; and diffused clustered (DC), in which aggregates of fluorescence are dispersed throughout the cytoplasm.

\section{Western blotting analysis of ERK $1 / 2$ phosphorylation in oocytes}

Total protein was extracted from 387 COCs after IVM $(n=100$, 96,90 and 101 from Groups $0 \mathrm{E}, 100 \mathrm{E}, 200 \mathrm{E}$ and $400 \mathrm{E}$ respectively). COCs were denuded by gentle pipetting and washed four times in PBS with $0.1 \%$ PVP. CCs were recovered and centrifuged twice in PBS with $0.1 \% \mathrm{w} / \mathrm{v}$ PVP at $700 \mathrm{~g}$ for $5 \mathrm{~min}$ at room temperature. The supernatant was removed and the cells and oocytes were homogenised in cold lysis buffer containing an EDTA-free protease inhibitor cocktail (Roche Diagnostics SL, Applied Science) in centrifuge tubes, snap frozen in liquid nitrogen and stored at $-80^{\circ} \mathrm{C}$ until assay. The western blot procedure followed the protocol reported by Garcia-Garcia et al. (2018). Briefly, samples were dissolved in protein sample buffer (5\% 2- $\beta$-mercaptoethanol and Laemmli), boiled for $5 \mathrm{~min}$ and centrifuged at $3000 \mathrm{~g}$ for $1 \mathrm{~min}$ at room temperature. The supernatant containing soluble proteins was divided into two aliquots and each one was separated by sodium dodecyl sulfate polyacrylamide gel electrophoresis ( $12 \%$ acrylamide plus bisacrylamide) and electrotransferred to nitrocellulose membranes. The membranes were probed with the primary antibody and incubated at $4^{\circ} \mathrm{C}$ overnight. The antibodies used were antiERK1/2 (MK1; Santa Cruz Biotechnology) and anti-phosphorylated (p) ERK1/2 (Santa Cruz Biotechnology) diluted $1: 200$ in blocking solution (LiCor Biotechnology) containing $0.2 \% \mathrm{v} / \mathrm{v}$ Tween-20. After incubation, membranes were washed four times for 5 min each time at room temperature in PBS 
$+0.2 \% \mathrm{v} / \mathrm{v}$ Tween- 20 with gentle shaking. Then, membranes were incubated for $45 \mathrm{~min}$ at room temperature in the dark with the secondary antibodies (goat anti-mouse for ERK and donkey anti-mouse for pERK1/2; $1: 15000$ dilution; LiCor Biotechnology). $\beta$-Actin (Sigma Aldrich A2228) was immunodetected with mouse monoclonal antibody as a loading control. The integrated density of bands was quantified using ImageJ (http:// rsbweb.nih.gov/ij/, verified 13 June 2018). The level of ERK activation in each treatment group was measured as the ratio of activated $\mathrm{pERK} 1 / 2$ to total ERK1/2 after normalisation against $\beta$-actin.

\section{Cumulus cell apoptosis}

The presence of apoptotic cells was detected by terminal deoxyribonucleotidyl transferase-mediated dUTP-digoxigenin nick end-labelling (TUNEL) in 41 COCs in total $(n=10,11,10$ and 10 in Groups 0E, 100E, 200E and 400E respectively) after IVM. Strand DNA breaks that had occurred during the cell apoptosis process were detected using an In Situ Cell Death Detection Kit, POD (Roche Diagnostics SL, Applied Science), as described previously (Arias-Álvarez et al. 2010, 2017). COCs were counterstained with $0.25 \mu \mathrm{g} \mathrm{mL}^{-1}$ propidium iodide (PI) for $15 \mathrm{~min}$ at $37^{\circ} \mathrm{C}$, and mounted between a coverslip and glass slide in incubation in mounting solution (ProLong Gold Antifade Reagent; Invitrogen). Samples were examined with laser scanning confocal microscopy (TCS SP2; Leica) using a 488-nm excitation laser to visualise TUNEL-positive cells and a 546-nm excitation laser to assess red fluorescence. Images were taken every $5 \mu \mathrm{m}$ and then analysed individually using ImageJ software (http://rsbweb.nih.gov/ij/, verified 13 June 2018). The apoptosis index was calculated as the ratio of green (TUNELpositive) to red (PI-positive) areas multiplied by 100 . Maximal projection was obtained with all sections taken in each COC to visualise the whole apoptotic area.

\section{RNA extraction and reverse transcription in COCs}

The abundance of mRNAs was analysed in 203 COCs $(n=51$, 50,50 and 52 in Groups $0 \mathrm{E}, 100 \mathrm{E}, 200 \mathrm{E}$ and $400 \mathrm{E}$ respectively) as previously described (Bermejo-Alvarez et al. 2010). Briefly, CCs were mechanically removed by gentle repeated pipetting, and groups of 10-12 oocytes and their corresponding CCs were analysed separately. Both oocytes and CCs were snap frozen in liquid nitrogen and stored at $-80^{\circ} \mathrm{C}$. Poly(A) RNA was prepared using the Dynabeads mRNA Direct Extraction Kit (Dynal Biotech, Invitrogen) according to the manufacturer's instructions with minor modifications (see Arias-Álvarez et al. 2013, 2017). The reverse transcription (RT) reaction (Bioline, Ecogen) was performed using poly $(\mathrm{T})$ primer, random primers and Moloney murine leukaemia virus reverse transcriptase enzyme (MMLV high performance reverse transcriptase; Epicentre Biotechnologies) in a total volume of $40 \mu \mathrm{L}$ to produce cDNA. Tubes were heated to $70^{\circ} \mathrm{C}$ for $5 \mathrm{~min}$ to denature the secondary RNA structure. RT was completed with the addition of 50 units of reverse transcriptase. Then, the tubes were incubated at $25^{\circ} \mathrm{C}$ for $10 \mathrm{~min}$ to induce annealing of random primers, at $37^{\circ} \mathrm{C}$ for $60 \mathrm{~min}$ to allow for RNA retrotranscription and at $85^{\circ} \mathrm{C}$ for $5 \mathrm{~min}$ to denature the enzyme.
Quantitative real-time polymerase chain reaction in COCS

The mRNA transcripts were quantified using real-time quantitative RT-polymerase chain reaction (qRT-PCR), as described previously (Arias-Álvarez et al. 2013, 2017). The level of expression of each transcript is given relative to that of the housekeeping gene $\mathrm{H} 2 \mathrm{~A}$ histone family member $\mathrm{Z}$ $(H 2 A F Z)$. Briefly, all qPCR were performed in duplicate on a Rotorgene 6000 Real Time Cycler (Corbett Research) by adding $2 \mu \mathrm{L}$ of each sample to the PCR mix (GoTaq qPCR Master Mix; Promega) containing specific primers to amplify the housekeeping gene and genes related to important events in oocyte maturation, namely $S O D 2, G P X 1, C A T, T P 53, C A S P 3$, $A K T 1$ and G6PD. GJA1 and PTGS2 were quantified only in CCs because their expression is related to cell-to-cell communication and cumulus expansion (Feuerstein et al. 2007; Shao et al. 2016). Primer sequences and the approximate sizes of the amplified fragments of all transcripts are given in Table 1. Each pair of primers was previously validated (Arias-Álvarez et al. 2017) to achieve efficiencies close to 1 , and the comparative cycle threshold (CT) method was used to quantify expression levels as described by Schmittgen and Livak (2008). In each cycle, fluorescence was acquired at a temperature above the melting temperature of primer dimers to avoid primer-dimer artefacts. The cycle during the log-linear phase of the reaction at which fluorescence increased above background (threshold cycle) was determined for each sample. Within this region of the amplification curve, a difference of one cycle is equivalent to a doubling of the amplified PCR product. According to the comparative CT method, the $\triangle \mathrm{CT}$ value was calculated by subtracting the CT value for the housekeeping gene (endogenous control) from the $\mathrm{CT}$ value for each gene. The $\Delta \Delta \mathrm{CT}$ value was determined by subtracting the highest treatment $\Delta \mathrm{CT}$ value from all other $\Delta \mathrm{CT}$ values. Fold changes in the relative gene expression of the target were calculated using the formula $2^{-\Delta \Delta \mathrm{CT}}$

\section{Assessment of the developmental competence of oocytes}

The developmental competence of oocytes matured in vitro with $100 \mu \mathrm{M} \alpha$-tocopherol was evaluated by IVF and IVC procedures as described previously (Arias-Álvarez et al. 2017).

IVF was performed using a pool of heterospermic fresh semen collected using an artificial vagina from five adult studs. The sperm samples were diluted $1: 50$ in fertilisation medium (Tyrode's medium with $2 \mathrm{mM}$ sodium bicarbonate, $36 \mathrm{mM}$ sodium lactate, $1 \mathrm{mM}$ sodium pyruvate, $0.01 \% \mathrm{BSA}$ and $10 \mathrm{mg} \mathrm{mL}^{-1}$ heparin), washed with fertilisation medium and centrifuged twice at $1000 \mathrm{~g}$ for $5 \mathrm{~min}$ at room temperature each time.

Afterwards, spermatozoa underwent a swim-up procedure in $2 \mathrm{~mL}$ Tyrode's medium for $20 \mathrm{~min}$ under an atmosphere of $5 \% \mathrm{CO}_{2}$ in air with maximum humidity at $38^{\circ} \mathrm{C}$. The spermatozoa recovered from the supernatant were incubated for a further $6 \mathrm{~h}$ under the same conditions. Then, IVM and in vivomatured oocytes were coincubated with spermatozoa at a final concentration of $1 \times 10^{6}$ spermatozoa $\mathrm{mL}^{-1}$ for $4 \mathrm{~h}$ at $38^{\circ} \mathrm{C}$ in four-well dishes containing $50 \mathrm{COCs}$ in $500 \mathrm{~mL}$ Tyrode's 
Table 1. Oligonucleotide sequences used for amplification of genes of interest in rabbit (Oryctolagus cuniculus) oocytes and cumulus cells by quantitative reverse transcription-polymerase chain reaction

Abbreviations: bp, base pairs; $H 2 A F Z, H 2 A$ histone family member Z; GJA1, gap junction protein, alpha 1, $43 \mathrm{kDa}$; PTGS2, prostaglandin-endoperoxide synthase 2 (prostaglandin G/H synthase and cyclo-oxygenase); $A K T 1$, cellular cycle V-Akt murine thymoma viral oncogene homologue 1; G6PD, glucose-6phosphate dehydrogenase; $G A P D H$, glyceraldehyde-3-phosphate dehydrogenase; SOD2, superoxide dismutase 2, mitochondrial; GPXI, glutathione peroxidase 1; $C A T$, catalase; TP53, apoptosis tumour protein 53; $C A S P 3$, caspase 3, apoptosis-related cysteine protease

\begin{tabular}{|c|c|c|c|}
\hline Gene & Primer sequence $\left(5^{\prime}-3^{\prime}\right)$ & Fragment size (bp) & GenBank Accession no. \\
\hline$H 2 A F Z$ & $\begin{array}{l}\text { Forward: AGGACGACTAGCCATGGACGTGTG } \\
\text { Reverse: CCACCACCAGCAATTGTAGCCTTG }\end{array}$ & 212 & NM_016750 \\
\hline$G J A I$ & $\begin{array}{l}\text { Forward: TGCCTTTCGTTGTAACACTCA } \\
\text { Reverse: AGAACACATGAGCCAAGTACA }\end{array}$ & 142 & NM_001198948.1 \\
\hline$P T G S 2$ & $\begin{array}{l}\text { TCCAAGCTGGCCTCACTGATGG } \\
\text { AGCATGTGTGTGGCCCGACTTG }\end{array}$ & 169 & NM_001082388.1 \\
\hline$A K T 1$ & $\begin{array}{l}\text { Forward: CACCACTGGATTTCTCTGCCT } \\
\text { Reverse: GGTACCGTTTGTTGACTGTGC }\end{array}$ & 230 & XM_008257300.1 \\
\hline$G 6 P D$ & $\begin{array}{l}\text { Forward: CTGATCCTGGGTCGCTTCAT } \\
\text { Reverse: ACGTACATGGGCACAAAACCA }\end{array}$ & 68 & NM_174602.2 \\
\hline$G A D P H$ & $\begin{array}{l}\text { Forward: CGCTGGGACGGGGTGCCCTTCATC } \\
\text { Reverse: CGCCAGGCCTCCCGCAGTTCATCA }\end{array}$ & 347 & XM_583628.4 \\
\hline$S O D 2$ & $\begin{array}{l}\text { Forward: GCTTACAGATTGCTGCTTGT } \\
\text { Reverse: AAGGTAATAAGCATGCTCCC }\end{array}$ & 101 & S67818.1 \\
\hline$G P X 1$ & $\begin{array}{l}\text { Forward: CTGCCCGCCTGGGAAATGCTGT } \\
\text { Reverse: CAGTCTCTCCTCCCCGGGCTGG }\end{array}$ & 328 & NM_001034349.2 \\
\hline$C A T$ & $\begin{array}{l}\text { Forward: TGACTGTTGCTGGAGACTGG } \\
\text { Reverse: TGTGCTTCTTCCTGTCGATG }\end{array}$ & 250 & NM_001076085.1 \\
\hline TP53 & $\begin{array}{l}\text { Forward: GTGCTGACCAGGGACACGGC } \\
\text { Reverse: CTGCACCAGGGCAGACCAGC }\end{array}$ & 223 & NM_001082404.1 \\
\hline$C A S P 3$ & $\begin{array}{l}\text { Forward: ACCCAGAAGACTGTGGATGG } \\
\text { Reverse: AYGCCTGCTTCACCACCTTC }\end{array}$ & 247 & $\mathrm{BC} 102589$ \\
\hline
\end{tabular}

medium per well. After coincubation, presumptive zygotes were denuded by gentle pipetting and cultured in TCM-199 supplemented with $20 \%$ FCS. Then, groups of 25 zygotes were placed in $25-\mu \mathrm{L}$ droplets of culture medium overlaid with mineral oil and incubated for $96 \mathrm{~h}$ under an atmosphere of $5 \% \mathrm{CO}_{2}, 5 \% \mathrm{O}_{2}$ in air with a maximum humidity at $38.5^{\circ} \mathrm{C}$. Differences in oocyte developmental competence between in vivo-matured and IVM oocytes were scored based on embryo development at 24, 48, 72 and 96 h post-insemination (h.p.i.). Embryos were classified on the basis of conventional morphological criteria according to their developmental stage following the guidelines of the International Embryo Transfer Society (www.iets.org, verified 13 June 2018). Morulae and blastocyst rates were expressed as a percentage of the total number of cleaved zygotes.

\section{Statistical analysis}

Data were analysed using SPSS ver. 19s (IBM, SPSS Inc.). The Shapiro-Wilk test was used to assess normality. MII rate, mitochondrial patterns and in vitro early embryo development were compared using Pearson's Chi-squared test. Comparisons of the apoptosis rate, ERK $1 / 2$ phosphorylation and gene expression between groups were made using one-way analysis of variance (ANOVA) followed by Bonferroni's post hoc test. Non-parametric samples were analysed by the Kruskal-Wallis test. All data are expressed as the mean \pm s.e.m. Differences were considered significant at two-tailed $P<0.05$.

\section{Results}

Nuclear maturation and ERK1/2 phosphorylation in oocytes

The MII rate increased in the $100 \mu \mathrm{M} \alpha$-tocopherol-supplemented compared with control group, but there were no significant differences in MII rate between the $0 \mathrm{E}, 100 \mathrm{E}, 200 \mathrm{E}$ and $400 \mathrm{E}$ groups $(63.4 \%, 81.2 \%, 65.0 \%$ and $77.8 \%$ respectively). ERK1/2 activation was evaluated in oocytes and their corresponding CCs. The ratio of pERK $1 / 2$ to total ERK $1 / 2$ in $\mathrm{CCs}$ and oocytes did not show significant concentrationdependent changes following antioxidant supplementation of the culture medium during IVM (Fig. 1).

\section{Mitochondrial relocation in the oocyte}

Mitochondrial migration patterns are compatible with cytoplasmic oocyte maturation, with diffuse patterns compatible with cytoplasmically immature oocytes in the rabbit. As indicated in Table 2, the percentage of oocytes with a non-migrated pattern was significantly lower in the $100 \mathrm{E}$ group compared with all other $\alpha$-tocopherol concentrations tested $(P<0.05)$. The $200 \mathrm{E}$ group showed a lower percentage of migrated patterns compared with the other groups $(P<0.05)$ and the highest rate of non-migrated oocytes $(P<0.05)$, due primarily to an increase in the DH pattern $(P<0.05)$. Groups $0 \mathrm{E}$ and $400 \mathrm{E}$ showed similar results. 
(a)

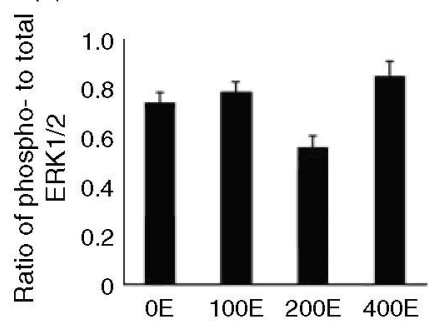

(b)

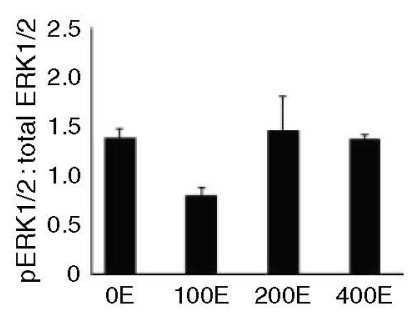

Fig. 1. Effect of different concentrations of $\alpha$-tocopherol in the IVM medium on extracellular signal-regulated kinase (ERK) $1 / 2$ activation of rabbit cumulus-oocyte complexes. Kinase activation after each treatment is shown as the ratio of phosphorylated (p) to total ERK1/2 in $(a)$ cumulus cells and (b) oocytes matured in the presence of $0,100,200$ or $400 \mu \mathrm{M}$ $\alpha$-tocopherol $(0 \mathrm{E}, 100 \mathrm{E}, 200 \mathrm{E}$ and $400 \mathrm{E}$ respectively). Data are the mean \pm s.e.m.

Table 2. Mitochondrial migration patterns observed in rabbit (Oryctolagus cuniculus) oocytes after IVM with $0,100,200$ and $400 \mu \mathrm{M} \alpha$ tocopherol (Groups $0 \mathrm{E}, 100 \mathrm{E}, 200 \mathrm{E}$ and $400 \mathrm{E}$ respectively) Within columns, different letters indicate significant differences $(P<0.05)$. $\mathrm{MC}$, migrated clustered; $\mathrm{MH}$, migrated homogeneous; $\mathrm{DC}$, diffused clustered; $\mathrm{DH}$, diffused homogeneous

\begin{tabular}{lllll}
\hline & $0 \mathrm{E}$ & $100 \mathrm{E}$ & $200 \mathrm{E}$ & $400 \mathrm{E}$ \\
\hline No. of oocytes & 46 & 16 & 20 & 18 \\
Migrated (\%) & $54.3^{\mathrm{a}}$ & $75.0^{\mathrm{a}}$ & $30.0^{\mathrm{b}}$ & $44.4^{\mathrm{a}}$ \\
MC (\%) & 15.2 & 50.0 & 20.0 & 27.8 \\
MH (\%) & 39.1 & 25.0 & 10.0 & 16.7 \\
Non-migrated (\%) & $45.7^{\mathrm{a}}$ & $25.0^{\mathrm{b}}$ & $70.0^{\mathrm{c}}$ & $55.6^{\mathrm{a}}$ \\
DC (\%) & 19.6 & 12.5 & 10.0 & 22.2 \\
DH (\%) & $26.1^{\mathrm{a}}$ & $12.5^{\mathrm{a}}$ & $60.0^{\mathrm{b}}$ & $33.3^{\mathrm{a}}$ \\
\hline
\end{tabular}

\section{Apoptotic rate in cumulus cells}

All concentrations of $\alpha$-tocopherol added to the IVM medium significantly reduced the mean apoptotic rate in CCs compared with the control group without antioxidant $(P<0.05)$. TUNELand PI-positive areas in COCs are shown in Fig. 2.

\section{Abundance of quality-related gene transcripts in COCs}

In oocytes, genes related with the antioxidant response, such as SOD2 and CAT, were significantly reduced when the IVM medium was supplemented with $100 \mu \mathrm{M} \alpha$-tocopherol compared with the control group without antioxidant (Fig. 3; $P<0.05$ ). In addition, the abundance of TP53 mRNA (related to DNA damage and the apoptosis cascade) was downregulated in oocytes in Group 100E compared with those in Group 0E $(P<0.05)$.

The relative abundance of the genes studied in CCs is shown in Fig. 4. SOD2 mRNA expression was significantly lower in Group 100E than in the control group $(P<0.05)$, whereas SOD2 mRNA expression in the rest of the groups was intermediate. Expression of $C A S P 3$, associated with activation of the apoptotic cascade, in CCs was significantly downregulated in groups with intermediate concentrations of the antioxidant $(100 \mathrm{E}$ and $200 \mathrm{E})$ compared with Groups $0 \mathrm{E}$ and $400 \mathrm{E}(P<0.05) . T P 53$ gene expression was slightly lower in Group $100 \mathrm{E}$ than Group $0 \mathrm{E}(P=0.07)$. The relative abundance of genes related to cumulus expansion, namely $G J A 1$ and $P T G S 2$, tended to downregulated $(P=0.1)$ after the addition of $\alpha$-tocopherol compared with the control group without antioxidant. The relative abundance of the other transcripts in oocytes and their CCs was similar among experimental groups.

\section{Developmental competence of IVM oocytes with $\alpha$-tocopherol}

As indicated in Table 3 , the kinetics of early embryo development were affected by embryo origin (in vitro or in vivo) and the IVM medium used. Both cleavage rate after IVF and blastocyst rate increased significantly $(P<0.01)$ in embryos derived from ovulated oocytes compared with those derived from IVM oocytes. No differences in cleavage rate were found between groups of in vitro-derived oocytes. However, when $\alpha$-tocopherol was included in the serum-free IVM medium (Group 100E), a higher number of morulae was found at 48 and 72 h.p.i. ( $P=0.06$ and $P<0.01$ respectively), compared with the IVM group without $\alpha$-tocopherol (0E). Blastocyst percentage was similar between both groups (see Fig. S1, available as Supplementary Material to this paper).

The use of an IVM medium with FCS and growth factors improved the kinetics of early embryo development in vitro. The percentage of early morulae at 48 h.p.i. $(P=0.06)$, morulae at 72 h.p.i. $(P<0.01)$ and compacted morulae at 96 h.p.i. $(P=0.06)$ was enhanced in the 0 E-FCS compared with $0 \mathrm{E}$ group. However, when $\alpha$-tocopherol was included in the IVM medium enriched with FCS and growth factors (100E-FCS), blastocyst yield was significantly improved $(P<0.01)$ compared with the IVM group without $\alpha$-tocopherol (0E-FCS) and with both IVM groups without FCS $(100 \mathrm{E}$ and $0 \mathrm{E})$.

\section{Discussion}

The present study provides a novel description of some important nuclear and cytoplasmic events associated with the maturation process in oocytes and their surrounding cumulus cells when the IVM medium is supplemented with different concentrations of $\alpha$-tocopherol. The results indicate that $\alpha$ tocopherol can regulate cell function during oocyte maturation and protect against the harmful effects of ROS produced by IVM. Under the conditions in the present study, $\alpha$-tocopherol supported oocyte nuclear and cytoplasmic maturation. It also reduced the apoptotic rate in $\mathrm{CCs}$ and induced changes in mRNA transcripts related to antioxidant response, cell cycle regulation and the apoptotic cascade and cumulus expansion in COCs, thereby improving the blastocyst rate after IVF and IVC.

In accordance with the unchanged pattern of nuclear maturation rate, ERK1/2 phosphorylation was not substantially modified in oocytes matured with in the presence of different concentrations of $\alpha$-tocopherol. Meiotic maturation of mammalian oocytes (transition to MII) goes together with changes in the protein phosphorylation pattern (Kastrop et al. 1990; Gall et al. 1993). One of the most important kinases or kinase 
(a)

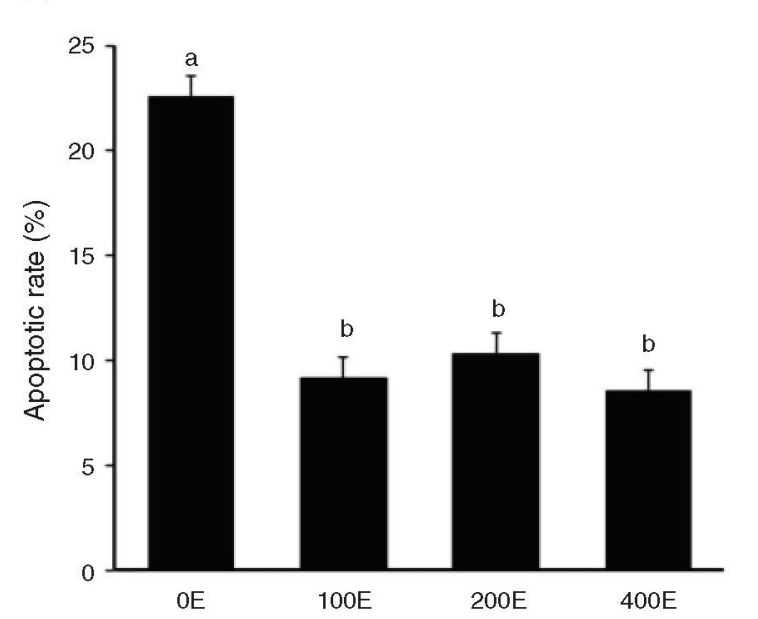

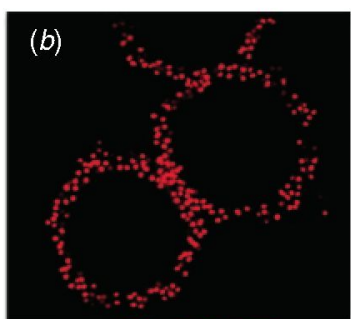

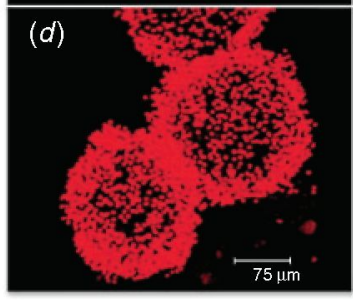

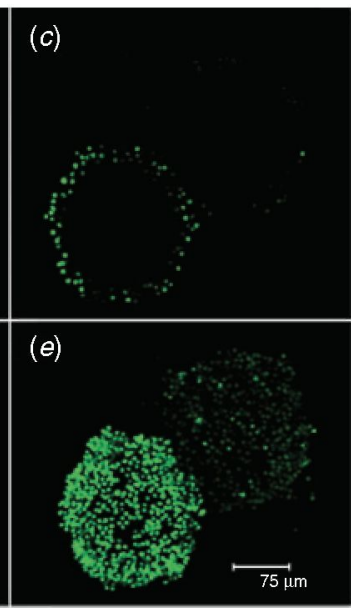

Fig. 2. (a) Apoptotic rate in rabbit cumulus cells after IVM with $0,100,200$ or $400 \mu \mathrm{M} \alpha$-tocopherol $(0 \mathrm{E}, 100 \mathrm{E}, 200 \mathrm{E}$ and $400 \mathrm{E}$ respectively). Data are the mean \pm s.e.m. Different letters above columns indicate significant differences $(P<0.05)$. $(b-e)$ Cumulus cell apoptosis visualised by the terminal deoxyribonucleotidyl transferase-mediated dUTP-digoxigenin nick end-labelling (TUNEL) assay in rabbit cumulus-oocyte complexes (COCs) after IVM. (b) All cell nuclei are stained red with propidium iodide in the mid section; $(c)$ TUNEL-positive (green) staining of cells considered apoptotic in the mid section; $(d)$ maximal projection obtained with all sections acquired in each COC showing the nuclei of all cumulus cells stained with propidium iodide; $(e)$ maximal projection of the same COCs showing TUNEL-positive labelled cells considered apoptotic. Photographs were taken under a $\times 40$ objective.

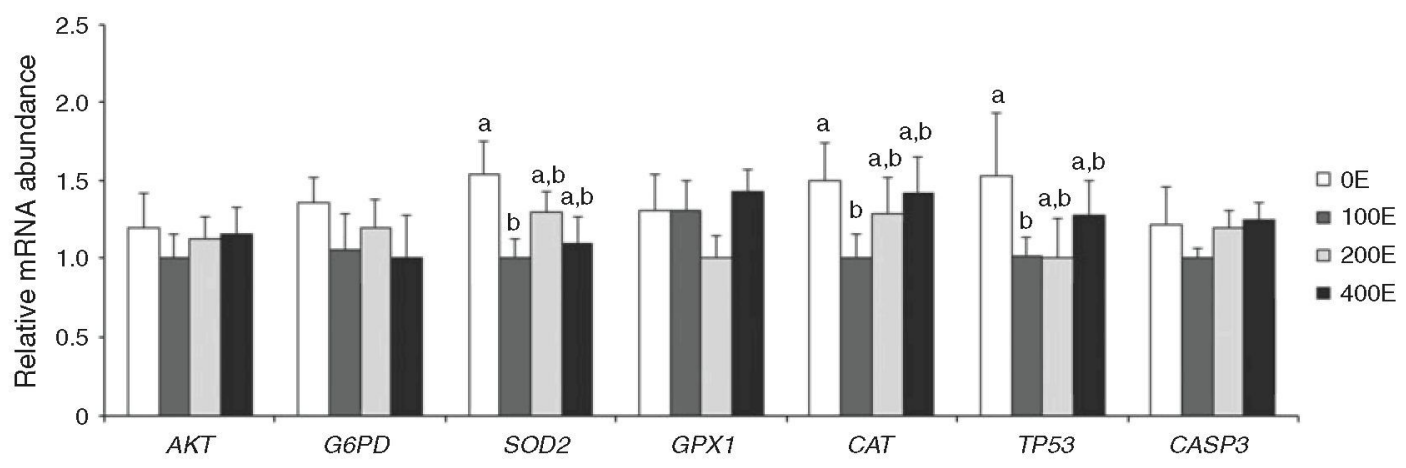

Fig. 3. Relative poly(A) mRNA abundance of seven candidate genes related to the cell cycle (cellular cycle V-Akt murine thymoma viral oncogene homologue 1 (AKTI)), glucose metabolism (glucose-6-phosphate dehydrogenase (G6PD)), oxidative response (superoxide dismutase 2, mitochondrial (SOD2), glutathione peroxidase 1 (GPXI), catalase (CAT)) and apoptosis (apoptosis tumour protein 53 (TP53), caspase 3, apoptosis-related cysteine protease (CASP3)) in rabbit oocytes after IVM with different concentrations of $\alpha$-tocopherol $(0,100,200$ or $400 \mu \mathrm{M}$; Groups $0 \mathrm{E}, 100 \mathrm{E}, 200 \mathrm{E}$ and $400 \mathrm{E}$ respectively). Data are the mean \pm s.e.m. Different letters above columns indicate significant differences $(P<0.05)$.

cascades supporting this process is ERK, as well as the kinase Akt. ERK1/2 act as intrafollicular mediators to stimulate CC expansion and play a key role in the acquisition of nuclear oocyte competence (Motlik et al. 1998; Duggavathi and Murphy 2009; Fan et al. 2009). In contrast, Akt is involved in the transition from MI to MII, polar body extrusion and organisation of microtubules (Hoshino and Sato 2008). The similar percentage of MII achieved and ERK $1 / 2$ phosphorylation observed in all experimental groups could be due to the effect of the similar concentrations of EGF included in the IVM medium, because EGF can activate ERK1/2 phosphorylation to support oocyte maturation and cumulus expansion (Fan et al. 2009). These results were confirmed with similar
AKT1 mRNA expression in CCs and oocytes. Therefore, the findings of the present study suggest that this natural antioxidant does not improve meiosis throughout IVM, as reported previously in COCs from rat (Takami et al. 1999), cattle (Dalvit et al. 2005) and sheep (Adeldust et al. 2015).

In the present study, two genes related to the cumulus expansion process were evaluated (PTGS2 and GJA1). COCs matured in vitro with $\alpha$-tocopherol showed slightly lower GJAI and $P T G S 2$ gene expression than the control group. GJA1, also known as connexin 43 , has been proposed as a major mediator of cell-to-cell communication via gap junctions (Gittens and Kidder 2005). As demonstrated previously, downregulation of $G J A I$ in CCs after oocyte maturation is associated with cumulus 


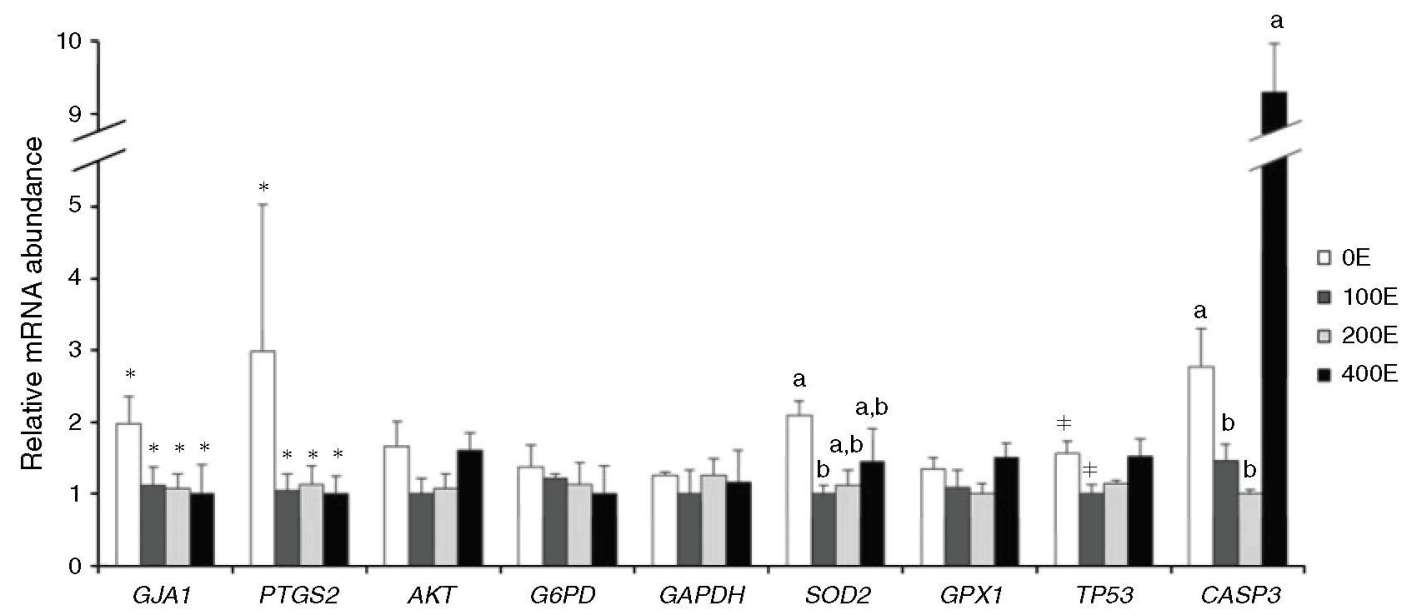

Fig. 4. Relative poly(A) mRNA abundance of eight candidate genes related to cumulus expansion (gap junction protein, alpha $1,43 \mathrm{kDa}(G J A I)$ and prostaglandin-endoperoxide synthase 2 (prostaglandin $\mathrm{G} / \mathrm{H}$ synthase and cyclo-oxygenase) (PTGS2)), cell cycle (cellular cycle V-Akt murine thymoma viral oncogene homologue 1 ( $A K T I)$ ), glucose metabolism (glucose-6-phosphate dehydrogenase $(G 6 P D)$, glyceraldehyde-3-phosphate dehydrogenase $(G A P D H)$ ), oxidative response (superoxide dismutase 2, mitochondrial (SOD2), glutathione peroxidase $1(G P X I)$ ) and apoptosis (apoptosis tumour protein 53 (TP53), caspase 3 , apoptosis-related cysteine protease (CASP3)) in rabbit cumulus cells after IVM with different concentrations of $\alpha$-tocopherol $(0,100,200$ or $400 \mu \mathrm{M}$; Groups $0 \mathrm{E}, 100 \mathrm{E}, 200 \mathrm{E}$ and $400 \mathrm{E}$ respectively). Data are the mean \pm s.e.m. Different letters above columns indicate significant differences $(P<0.05)$. Data with * differs at $P=0.1$, and with ${ }^{\ddagger}$ differs at $P=0.07$.

Table 3. Early development of rabbit (Oryctolagus cuniculus) embryos from oocytes after IVM in medium containing fetal calf serum (FCS) or not and supplemented with or without $100 \mu \mathrm{M} \alpha$-tocopherol (100E and $0 \mathrm{E}$ (control) respectively)

Unless indicated otherwise, data are given as $n(\%)$. Within columns, different letters indicate significant differences $(P<0.05)$; * indicates significant differences at $P=0.06$

\begin{tabular}{|c|c|c|c|c|c|c|}
\hline & $\begin{array}{l}\text { Presumptive } \\
\text { zygotes }(n)\end{array}$ & $\begin{array}{c}\text { Total cleaved } \\
\text { at } 24 \mathrm{~h}\end{array}$ & $\begin{array}{c}\text { Early morulae } \\
\text { at } 48 \mathrm{~h}\end{array}$ & $\begin{array}{l}\text { Morulae } \\
\text { at } 72 \mathrm{~h}\end{array}$ & $\begin{array}{c}\text { Compacted } \\
\text { morulae at } 96 \mathrm{~h}\end{array}$ & $\begin{array}{c}\text { Blastocysts } \\
\text { at } 96 \mathrm{~h}\end{array}$ \\
\hline \multicolumn{7}{|c|}{$I V M C O C s$} \\
\hline $0 \mathrm{E}$ & 128 & $25(19.5) \mathrm{a}$ & $0(0.0) \mathrm{a}^{*}$ & $0(0.0) \mathrm{a}$ & $3(12.0) \mathrm{a}^{*}$ & $0(0.0) \mathrm{a}$ \\
\hline $100 \mathrm{E}$ & 132 & $26(19.7) \mathrm{a}$ & $4(15.38) \mathrm{a}^{*}$ & $6(23.0) \mathrm{b}$ & $6(23.1) \mathrm{a}$ & $2(7.6) \mathrm{a}$ \\
\hline 0E-FCS & 128 & $24(18.8) \mathrm{a}$ & $4(16.6) \mathrm{a}$ & $8(33.3) b$ & $9(37.5) \mathrm{a}^{*}$ & $3(12.5) \mathrm{a}$ \\
\hline 100E-FCS & 127 & $28(22.0) \mathrm{a}$ & $1(3.5) \mathrm{a}$ & $6(21.4) b$ & $7(25.0) \mathrm{a}$ & $5(17.8) b$ \\
\hline In vivo-matured COCs & 103 & $48(46.6) \mathrm{b}$ & $28(58.3) \mathrm{b}$ & $36(75.0) \mathrm{c}$ & $32(66.6) b$ & $13(27.1) \mathrm{c}$ \\
\hline
\end{tabular}

expansion and reflects higher oocyte developmental competence in different species (Edry et al. 2006; Feuerstein et al. 2007; Shao et al. 2016; Arias-Álvarez et al. 2017). In contrast, PTGS2 is the key enzyme in prostaglandin E biosynthesis and is involved in the regulation of COC expansion during the ovulatory process in mice (Davis et al. 1999; Jang et al. 2015). PTGS2 mRNA abundance in CCs is positively correlated with in vitro oocyte quality in bovine (Assidi et al. 2008) and human (McKenzie et al. 2004), but not rabbit (Arias-Álvarez et al. 2017) COCs.

Mitochondrial activity and distribution are also associated with oocyte developmental competence, because mitochondria are the major intracellular source of energy through ATP production by oxidative phosphorylation and produce enzymes involved in the antioxidant defence of the cell. Analysis of mitochondrial migration revealed that $100 \mu \mathrm{M} \alpha$-tocopherol reduced the percentage of mitochondrial patterns, consistent with cytoplasmically immature oocytes in rabbit. Abnormal dynamics of mitochondrial reorganisation in the maturing oocyte are related to anomalous ATP content (Zhuang et al. 2012), mitochondrial dysfunction and increased ROS concentrations, and subsequently to cell damage (Torner et al. 2004; Lord and Aitken 2013). The primary ROS generated by the mitochondria, superoxide anion $\left(\cdot \mathrm{O}^{2-}\right)$, is converted by superoxide dismutase (SOD2) enzymes into $\mathrm{H}_{2} \mathrm{O}_{2}$ (Kowaltowski et al. 2009), followed by CAT transformation of $\mathrm{H}_{2} \mathrm{O}_{2}$ into water and oxygen (Khan et al. 2015). The results of the present study show that the inclusion of $100 \mu \mathrm{M} \alpha$-tocopherol reduces SOD2 and CAT poly(A) mRNA abundance in oocytes compared with the control group. SOD and CAT activities are lower in oocytes with lower levels of oxidative stress (Waiz et al. 2016). In fact, in mice and human MII oocytes, no CAT transcripts have been detected (El Mouatassim et al. 1999), and downregulation of SOD 2 mRNA transcripts is associated with higher oocyte 
developmental competence (Arias-Álvarez et al. 2017). In contrast, it has been reported that oocytes (Khalil et al. 2013) and embryos (Marques et al. 2018) with a better antioxidant defence show higher levels of endogenous antioxidant enzymes. These apparent discrepancies could be due to the addition of different types of antioxidants to the IVM medium and differences between species. In the present study, SOD2 gene expression was downregulated in CCs from the group supplemented with $100 \mu \mathrm{M} \alpha$-tocopherol compared with the group without antioxidant. This is in contrast with previous results in rabbit oocytes (Arias-Álvarez et al. 2017), in which increased SOD2 gene expression was related to a higher developmental competence. We hypothesise that the presence of $\alpha$-tocopherol in the IVM medium may enhance extrinsic antioxidant protection, which could possibly reduce the synthesis of endogenous antioxidant enzymes, such as SOD2, in CCs to basal levels to maintain the redox equilibrium. Future work should determine additional pathways to elucidate the mechanism of action of antioxidant protection on CCs.

The lower abundance of TP53 poly(A) transcripts in oocytes from Group $100 \mathrm{E}$ compared with Group $0 \mathrm{E}$ also supports the notion that this concentration of $\alpha$-tocopherol could protect the oocyte during maturation in rabbits. TP53 is involved in cell cycle regulation and DNA repair, leading to cell cycle arrest and apoptosis by regulating genes such as $C A S P 3$. The downregulation of both TP53 and CASP 3 in CCs following the addition of $100 \mu \mathrm{M} \alpha$-tocopherol to the IVM medium, together with the reduced apoptotic rate observed in this group, may suggest a higher quality of IVM CCs with an intermediate concentration of $\alpha$-tocopherol. Earlier studies found that $\alpha$-tocopherol could prevent follicular cells from undergoing apoptosis (MartínRomero et al. 2008; Tao et al. 2010; Asadi et al. 2012), but this effect depended on the concentration. In ruminants, higher concentrations of $\alpha$-tocopherol in the maturation medium decreased cleavage rates (Adeldust et al. 2015). In the present study, a significant increase in $C A S P 3$ gene expression was observed in Group 400E, but there was no increase in the apoptotic rate in these CCs. Previous studies have shown higher CASP3 gene expression is associated with a greater apoptotic rate (Yuan et al. 2005). However, activation of the caspase cascade is a previous step to morphological alterations visualised by TUNEL (for a review, see Savitskaya and Onishchenko 2015).

Changes in oocyte quality markers seen following $100 \mu \mathrm{M}$ $\alpha$-tocopherol supplementation resulted in a better embryo production in vitro. The percentage of morulae increased when $\alpha$-tocopherol was included in the IVM medium. However, these results only appeared to be consistent when $\alpha$-tocopherol was included in our previously tested IVM medium with FCS and growth factors (Lorenzo et al. 1996; Arias-Álvarez et al. 2010), with which a better blastocyst yield was found. Although FCS may contain a variety of compounds with antioxidant properties, present study demonstrates that embryo production was significantly enhanced only when $\alpha$-tocopherol was added to the FCSenriched IVM medium. These results are consistent with several reports of improvements in embryo development after the inclusion of antioxidants during IVM (Thiyagarajan and Valivittan 2009; Tao et al. 2010; Tareq et al. 2012; Farzollahi et al.
2016) or IVC (Olson and Seidel 2000; Natarajan et al. 2010). In addition, SCNT outcome is higher in the presence of $\alpha$-tocopherol, because it enhances cytoplasmic maturation of recipient oocytes, increases blastocyst formation and blocks DNA damage in transgenic embryos (Wongsrikeao et al. 2007). Recently, Yashiro et al. (2015) demonstrated the beneficial effects of $\alpha$ tocopherol on the revivability of vitrified-warmed oocytes, in which both blastocyst rate and quality were improved. However, some findings regarding the inclusion of antioxidants are controversial, because other studies have reported that antioxidant supplementation during IVM does not affect cleavage rates and embryo development towards the blastocyst stage (Dalvit et al. 2005; Adeldust et al. 2015), even though a decreased apoptotic rate was reported. This discrepancy may be related to the animal species used, the percentage oxygen tension during IVM, the source of oocytes or the composition of the maturation media used.

\section{Conclusions}

This study indicates that supplementation of the IVM medium with $100 \mu \mathrm{M} \alpha$-tocopherol improves oocyte quality in different ways: (1) it modifies mRNA transcripts, which reflect reduced oxidative stress (SOD2 and $C A T)$, cell damage and apoptotic cascade activation (TP53 and CASP) in oocytes and CCs; (2) it decreases the apoptotic rate in CCs; (3) it reduces the rate of cytoplasmically immature oocytes; and (4) it increases oocyte developmental competence, because early embryo development in vitro was improved. We propose that the presence of $\alpha$ tocopherol in rabbit IVM medium may reduce in vitro-derived oxidative stress in non-damaged rabbit oocytes. However, the blastocyst rate for embryos derived from IVM oocytes remains lower than that for embryos from in vivo-matured oocytes. Further work is warranted in order to explore the modulation of intracellular ROS production with a view to improving the IVM medium in this species.

\section{Conflicts of interest}

The authors declare no conflicts of interest.

\section{Acknowledgements}

This work was supported by funds from the Spanish Ministry of Economy and Competitiveness (AGL2015-66145, and AGL2015-65572-C2-2-R), Community of Madrid (S2013/ABI-2913) and Universidad Complutense de Madrid-Comunidad de Madrid research program (920249). The authors thank D. Rizos, E. Pericuesta and K. Nieto for their invaluable support with the experimental part of this study, and C. López Bote for HPLC analyses.

\section{References}

Adeldust, H., Zeinoaldini, S., Kohram, H., Amiri Roudbar, M., and Daliri Joupari, M. (2015). In vitro maturation of ovine oocyte in a modified granulosa cells co-culture system and alpha-tocopherol supplementation effects on nuclear maturation and cleavage. J. Anim. Sci. Technol. 57, 27. doi:10.1186/S40781-015-0061-5

Agarwal, A., Aponte-Mellado, A., Premkumar, B. J., Shaman, A., and Gupta, S. (2012). The effects of oxidative stress on female reproduction a review. Reprod. Biol. Endocrinol. 10, 49. doi:10.1186/1477-7827-10-49

Arias-Álvarez, M., García-García, R. M., Torres-Rovira, L., GonzálezBulnes, A., Rebollar, P. G., and Lorenzo, P. L. (2010). Influence of 
hormonal and nonhormonal estrus synchronization methods on follicular and oocyte quality in primiparous lactating does at early postpartum period. Theriogenology 73, 26-35. doi:10.1016/J.THERIOGENOL OGY.2009.07.017

Arias-Álvarez, M., García-García, R. M., Rebollar, P. G., Gutiérrez-Adán, A., López-Béjar, M., and Lorenzo, P. L. (2013). Ovarian response and embryo gene expression patterns after nonsuperovulatory gonadotropin stimulation in primiparous rabbits does. Theriogenology 79, 323-330. doi: 10.1016/J.THERIOGENOLOGY.2012.09.019

Arias-Álvarez, M., García-García, R. M., Lopez-Tello, J., Rebollar, P. G., Gutiérrez-Adán, A., and Lorenzo, P. L. (2017). In vivo and in vitro maturation of rabbit oocytes differently affects the gene expression profile, mitochondrial distribution, apoptosis and early embryo development. Reprod. Fertil. Dev. 29, 1667-1679. doi:10.1071/RD15553

Asadi, E., Jahanshahi, M., and Golalipour, M. J. (2012). Effect of vitamin E on oocytes apoptosis in nicotine-treated mice. Iran. J. Basic Med. Sci. 15, $880-884$.

Assidi, M., Dufort, I., Ali, A., Hamel, M., Algriany, O., Dielemann, S., and Sirard, M. A. (2008). Identification of potential markers of oocyte competence expressed in bovine cumulus cells matured with folliclestimulating hormone and/or phorbol myristate acetate in vitro. Biol. Reprod. 79, 209-222. doi:10.1095/BIOLREPROD.108.067686

Azzi, A., and Stocker, A. (2000). Vitamin E: non-antioxidant roles. Prog. Lipid Res. 39, 231-255. doi:10.1016/S0163-7827(00)00006-0

Bermejo-Alvarez, P., Rizos, D., Rath, D., Lonergan, P., and Gutiérrez-Adan, A. (2010). Sex determines the expression level of one third of the actively expressed genes in bovine blastocysts. Proc. Natl. Acad. Sci. USA 107, 3394-3399. doi:10.1073/PNAS.0913843107

Cassano, E., Tosto, L., Balestrieri, M., Zicarelli, L., and Abrescia, P. (1999). Antioxidant defense in the follicular fluid of water buffalo. Cell. Physiol. Biochem. 9, 106-116. doi:10.1159/000016307

Chow, C. K. (1991). Vitamin E and oxidative stress. Free Radic. Biol. Med. 11, 215-232. doi: 10.1016/0891-5849(91)90174-2

Combelles, C. M. H., Gupta, S., and Agarwal, A. (2009). Could oxidative stress influence the in-vitro maturation of oocytes? Reprod. Biomed. Online 18, 864-880. doi:10.1016/\$1472-6483(10)60038-7

Dalvit, G., Llanes, S. P., Descalzo, A., Insani, M., Beconi, M., and Cetica, P. (2005). Effect of alpha-tocopherol and ascorbic acid on bovine oocyte in vitro maturation. Reprod. Domest. Anim. 40, 93-97. doi:10.1111/J. 1439-0531.2004.00522.X

Davis, B. J., Lennard, D. E., Lee, C. A., Tiano, H. F., Morham, S. G., Wetsel, W. C., and Langenbach, R. (1999). Anovulation in cyclooxygenase-2deficient mice is restored by prostaglandin $\mathrm{E}_{2}$ and interleukin-1beta. Endocrinology 140, 2685-2695. doi:10.1210/ENDO.140.6.6715

Duggavathi, R., and Murphy, B. D. (2009). Ovulation signals. Science 324, 890-891. doi:10.1126/SCIENCE.1174130

Edry, I., Sela-Abramovich, S., and Dekel, N. (2006). Meiotic arrest of oocytes depends on cell-to-cell communication in the ovarian follicle. Mol. Cell. Endocrinol. 252, 102-106. doi:10.1016/J.MCE.2006.03.009

El Mouatassim, S., Guérin, P., and Ménézo, Y. (1999). Expression of genes encoding antioxidant enzymes in human and mouse oocytes during the final stages of maturation. Mol. Hum. Reprod. 5, 720-725. doi:10.1093/ MOLEHR/5.8.720

Fan, J., and Watanabe, T. (2003). Transgenic rabbits as therapeutic protein bioreactors and human disease models. Pharmacol. Ther. 99, 261-282. doi:10.1016/S0163-7258(03)00069-X

Fan, H. Y., Liu, Z., Shimada, M., Sterneck, E., Johnson, P. F., Hedrick, S. M., and Richards, J. S. (2009). MAPK3/1 (ERK1/2) in ovarian granulosa cells are essential for female fertility. Science 324, 938-941. doi:10. 1126/SCIENCE. 1171396

Farzollahi, M., Tayefi-Nasrabadi, H., Mohammadnejad, D., and Abedelahi, A. (2016). Supplementation of culture media with vitamin $E$ improves mouse antral follicle maturation and embryo development from vitrified ovarian tissue. J. Obstet. Gynaecol. Res. 42, 526-535. doi:10.1111/JOG. 12933

Feuerstein, P., Cadoret, V., Dalbies-Tran, R., Guerif, F., Bidault, R., and Royere, D. (2007). Gene expression in human cumulus cells one approach to oocyte competence. Hum. Reprod. 22, 3069-3077. doi:10. 1093/HUMREP/DEM336

Fischer, B., Chavatte-Palmer, P., Viebahn, C., Navarrete-Santos, A., and Duranthon, V. (2012). Rabbit as a reproductive model for human health. Reproduction 144, 1-10. doi:10.1530/REP-12-0091

Gall, L., Le Gal, F., and De Smedt, V. (1993). Protein phosphorylation pattern during in vitro maturation of goat oocytes. Mol. Reprod. Dev. 36, 500-506. doi: 10.1002/MRD.1080360415

Garcia-Garcia, R. M., Masdeu, M., Sanchez-Rodriguez, A., Millan, P., Arias-Alvarez, M., Sakr, O. G., Bautista, J. M., Castellini, C., Lorenzo, P. L., and Rebollar, P. G. (2018). $\beta$-Nerve growth factor identification in male rabbit genital tract and seminal plasma and its role in ovulation induction in rabbit does. Ital. J. Anim. Sci. 17, 442-453. doi:10.1080/ 1828051X.2017.1382315

Gittens, J. E., and Kidder, G. M. (2005). Differential contributions of connexin 37 and connexin 43 to oogenesis revealed in chimeric reaggregated mouse ovaries. J. Cell Sci. 118, 5071-5078. doi:10.1242/JCS. 02624

Guérin, P., El Mouatassim, S., and Ménézo, Y. (2001). Oxidative stress and protection against reactive oxygen species in the pre-implantation embryo and its surroundings. Hum. Reprod. Update 7, 175-189. doi:10.1093/HUMUPD/7.2.175

Hoshino, Y., and Sato, E. (2008). Protein kinase B (PKB/Akt) is required for the completion of meiosis in mouse oocytes. Dev. Biol. 314, 215-223. doi:10.1016/J.YDBIO.2007.12.005

Jang, Y. J., Park, J. I., Moon, W. J., Dam, P. T., Cho, M. K., and Chun, S. Y. (2015). Cumulus cell-expressed type I interferons induce cumulus expansion in mice. Biol. Reprod. 92, 20. doi:10.1095/BIOLREPROD. 114.122770

Jeong, Y. W., Park, S. W., Hossein, M. S., Kim, S., Kim, J. H., Lee, S. H., Kang, S. K., Lee, B. C., and Hwang, W. S. (2006). Antiapoptotic and embryotrophic effects of alpha-tocopherol and L-ascorbic acid on porcine embryos derived from in vitro fertilization and somatic cell nuclear transfer. Theriogenology 66, 2104-2112. doi:10.1016/J.THER IOGENOLOGY.2006.06.007

Kastrop, P. M., Bevers, M. M., Destree, O. H., and Kruip, T. A. (1990). Changes in protein synthesis and phosphorylation patterns during bovine oocyte maturation in vitro. J. Reprod. Fertil. 90, 305-310. doi:10.1530/ JRF.0.0900305

Khalil, W. A., Marei, W. F., and Khalid, M. (2013). Protective effects of antioxidants on linoleic acid-treated bovine oocytes during maturation and subsequent embryo development. Theriogenology 80, 161-168. doi:10.1016/J.THERIOGENOLOGY.2013.04.008

Khan, S. N., Shaeib, F., Najafi, T., Kavdia, M., Gonik, B., Saed, G. M., Goud, P. T., and Abu-Soud, H. M. (2015). Diffused intra-oocyte hydrogen peroxide activates myeloperoxidase and deteriorates oocyte quality. PLoS One 10, e0132388. doi:10.1371/JOURNAL.PONE.0132388

Kitagawa, Y., Suzuki, K., Yoneda, A., and Watanabe, T. (2004). Effects of oxygen concentration and antioxidants on the in vitro developmental ability, production of reactive oxygen species (ROS), and DNA fragmentation in porcine embryos. Theriogenology 62, 1186-1197. doi:10. 1016/J.THERIOGENOLOGY.2004.01.011

Kowaltowski, A. J., de Souza-Pinto, N. C., Castilho, R. F., and Vercesi, A. E. (2009). Mitochondria and reactive oxygen species. Free Radic. Biol. Med. 47, 333-343. doi:10.1016/J.FREERADBIOMED.2009.05.004

López-Tello, J., Arias-Álvarez, M., Jiménez-Martínez, M. Á., BarberoFernández, A., García-García, R. M., Rodríguez, M., Lorenzo, P. L., Torres-Rovira, L., Astiz, S., González-Bulnes, A., and Rebollar, P. G. (2017). The effects of sildenafil citrate on feto-placental development 
and haemodynamics in a rabbit model of intrauterine growth restriction. Reprod. Fertil. Dev. 29, 1239-1248. doi:10.1071/RD15330

Lord, T., and Aitken, R. J. (2013). Oxidative stress and ageing of the post-ovulatory oocyte. Reproduction 146, R217-R227. doi:10.1530/ REP-13-0111

Lorenzo, P. L., Rebollar, P. G., Illera, M. J., Illera, J. C., Illera, M., and Alvariño, J. M. (1996). Stimulatory effect of insulin-like growth factor I and epidermal growth factor on the maturation of rabbit oocytes in vitro. J. Reprod. Fertil. 107, 109-117. doi:10.1530/JRF.0.1070109

Marques, T. C., da Silva Santos, E. C., Diesel, T. O., Leme, L. O., Martins, C. F., Dode, M., Alves, B. G., Costa, F., de Oliveira, E. B., and Gambarini, M. L. (2018). Melatonin reduces apoptotic cells, SOD2 and HSPB1 and improves the in vitro production and quality of bovine blastocysts. Reprod. Domest. Anim. 53, 226-236. doi:10.1111/RDA. 13097

Martín-Romero, F. J., Miguel-Lasobras, E. M., Domínguez-Arroyo, J. A., González-Carrera, E., and Alvarez, I. S. (2008). Contribution of culture media to oxidative stress and its effect on human oocytes. Reprod. Biomed. Online 17, 652-661. doi:10.1016/S1472-6483(10)60312-4

McCluskey, S., Hall, M., Stanton, C., and Devery, R. (1999). Alphatocopherol inhibits oxidative stress induced by cholestanetriol and 25-hydroxycholesterol in porcine ovarian granulosa cells. Mol. Cell. Biochem. 194, 217-225. doi:10.1023/A:1006967219894

McKenzie, L. J., Pangas, S. A., Carson, S. A., Kovanci, E., Cisneros, P., Buster, J. E., Amato, P., and Matzuk, M. M. (2004). Human cumulus granulosa cell gene expression: a predictor of fertilization and embryo selection in women undergoing IVF. Hum. Reprod. 19, 2869-2874. doi:10.1093/HUMREP/DEH535

Motlik, J., Pavlok, A., Kubelka, M., Kalous, J., and Kalab, P. (1998). Interplay between $\mathrm{CDC} 2$ kinase and MAP kinase pathway during maturation of mammalian oocytes. Theriogenology 49, 461-469. doi:10.1016/S0093-691X(97)00418-4

Natarajan, R., Shankar, M., and Munuswamy, D. (2010). Effect of $\alpha$-tocopherol supplementation on in vitro maturation of sheep oocytes and in vitro development of preimplantation sheep embryos to the blastocyst stage. J. Assist. Reprod. Genet. 27, 483-490. doi:10.1007/ S10815-010-9430-7

Ogonuki, N., Inoue, K., Miki, H., Mochida, K., Hatori, M., Okada, H., Takeiri, S., Shimozawa, N., Nagashima, H., Sankai, T., and Ogura, A. (2005). Differential development of rabbit embryos following microinsemination with sperm and spermatids. Mol. Reprod. Dev. 72, 411417. doi:10.1002/MRD.20363

Olson, S. E., and Seidel, G. E., Jr (2000). Culture of in vitro-produced bovine embryos with vitamin $\mathrm{E}$ improves development in vitro and after transfer to recipients. Biol. Reprod. 62, 248-252. doi:10.1095/BIOLRE PROD62.2.248

Palini, S., Benedetti, S., Tagliamonte, M. C., De Stefani, S., Primiterra, M., Polli, V., Rocchi, P., Catalani, S., Battistelli, S., Canestrari, F., and Bulletti, C. (2014). Influence of ovarian stimulation for IVF/ICSI on the antioxidant defence system and relationship to outcome. Reprod. Biomed. Online 29, 65-71. doi:10.1016/J.RBMO.2014.03.010

Rizos, D., Ward, F., Duffy, P., Boland, M. P., and Lonergan, P. (2002). Consequences of bovine oocyte maturation, fertilization or early embryo development in vitro versus in vivo implications for blastocyst yield and blastocyst quality. Mol. Reprod. Dev. 61, 234-248. doi:10.1002/ MRD.1153

Savitskaya, M. A., and Onishchenko, G. E. (2015). Mechanisms of apoptosis. Biochemistry 80, 1393-1405. doi:10.1134/S0006297915110012
Schmittgen, T. D., and Livak, K. J. (2008). Analyzing real-time PCR data by the comparative C(T) method. Nat. Protoc. 3, 1101-1108. doi:10.1038/ NPROT.2008.73

Schweigert, F. J., Steinhagen, B., Raila, J., Siemann, A., Peet, D., and Buscher, U. (2003). Concentrations of carotenoids, retinol and $\alpha$ tocopherol in plasma and follicular fluid of women undergoing IVF. Hum. Reprod. 18, 1259-1264. doi:10.1093/HUMREP/DEG249

Shao, L., Chian, R. C., Xu, Y., Yan, Z., Zhang, Y., Gao, C., Gao, L., Liu, J., and Cui, Y. (2016). Genomic expression profiles in cumulus cells derived from germinal vesicle and MII mouse oocytes. Reprod. Fertil. Dev. 28, 1798-1809. doi:10.1071/RD15077

Takami, M., Preston, S., Toyloy, V., and Behrman, H. (1999). Antioxidants reversibly inhibit the spontaneous resumption of meiosis. Am. J. Physiol 276, E684-E688. doi:10.1152/AJPENDO.1999.276.4.E684

Tao, Y., Chen, H., Tian, N., Huo, D., Li, G., Zhang, Y., Liu, Y., Fang, F., Ding, J., and Zhang, X. (2010). Effects of L-ascorbic acid, $\alpha$-tocopherol and co-culture on in vitro developmental potential of porcine cumulus cells free oocytes. Reprod. Domest. Anim. 45, 19-25. doi:10.1111/J 1439-0531.2008.01129.X

Tareq, K. M., Akter, Q. S., Khandoker, M. A., and Tsujii, H. (2012) Selenium and vitamin $\mathrm{E}$ improve the in vitro maturation, fertilization and culture to blastocyst of porcine oocytes. J. Reprod. Dev. 58, 621628. doi:10.1262/JRD.2012-064

Thiyagarajan, B., and Valivittan, K. (2009). Ameliorating effect of vitamin $\mathrm{E}$ on in vitro development of preimplantation buffalo embryos. J. Assist. Reprod. Genet. 26, 217-225. doi:10.1007/S10815-009-9302-1

Torner, H., Brüsow, K., Alm, H., Ratky, J., Pöhland, R., Tuchscherer, A., and Kamitz, W. (2004). Mitochondrial aggregation patterns and activation in porcine oocytes and apoptosis in surrounding cumulus cells depends on the stage of pre-ovulatory maturation. Theriogenology 61, 1675-1689. doi:10.1016/J.THERIOGENOLOGY.2003.09.013

Tripathi, A., Khatun, S., Pandey, A., Mishra, S., Chaube, R., Shrivastau, T., and Chaube, S. (2009). Intracellular levels of hydrogen peroxide and nitric oxide in oocytes at various stages of meiotic cell cycle and apoptosis. Free Radical Research 43, 287-294.

Waiz, S. A., Raies-Ul-Haq, M., Dhanda, S., Kumar, A., Goud, T. S., Chauhan, M. S., and Upadhyay, R. C. (2016). Heat stress and antioxidant enzyme activity in bubaline (Bubalus bubalis) oocytes during in vitro maturation. Int. J. Biometeorol. 60, 1357-1366. doi:10.1007/S00484015-1129-0

Wongsrikeao, P., Nagai, T., Agung, B., Taniguchi, M., Kunishi, M., Suto, S., and Otoi, T. (2007). Improvement of transgenic cloning efficiencies by culturing recipient oocytes and donor cells with antioxidant vitamins in cattle. Mol. Reprod. Dev. 74, 694-702. doi:10.1002/MRD.20640

Yashiro, I., Tagiri, M., Ogawa, H., Tashima, K., Takashima, S., Hara, H., Hirabayashi, M., and Hochi, S. (2015). High revivability of vitrifiedwarmed bovine mature oocytes after recovery culture with $\alpha$-tocopherol Reproduction 149, 347-355. doi:10.1530/REP-14-0594

Yuan, Y. Q., Van Soom, A., Leroy, J. L., Dewulf, J., Van Zeveren, A., de Kruif, A., and Peelman, L. J. (2005). Apoptosis in cumulus cells, but not in oocytes, may influence bovine embryonic developmental competence. Theriogenology 63, 2147-2163. doi:10.1016/J.THERIOGENOL OGY.2004.09.054

Zhuang, X. J., Huang, Y., Duan, Y. P., Zhang, M., Lu, Y. Q., and Lu, K. H. (2012). Translocation of active mitocondria during buffalo (Bubalus bubalis) oocytes in vitro maturation, fertilization and preimplantation embryo development. Reprod. Domest. Anim. 47, 443-448. doi:10.1111/ J.1439-0531.2011.01900.X 